\title{
5 Scalar biases in solar photovoltaic uptake
}

\section{Socio-materiality, regulatory inertia and politics}

\author{
Siddharth Sareen
}

\section{The governance of solar energy rollout: from global South to global North}

The need for an integrated focus on the governance of solar energy rollout

During the 2010s, solar photovoltaics (PV) became the fastest-growing energy technology worldwide. Ninety-seven giga watts (GW) of solar capacity was installed in 2019 alone, which equalled 55\% of all renewable energy capacity added that year. At the start of the 2020s, globally installed solar capacity stood at $580 \mathrm{GW}$, or $23 \%$ of $2,537 \mathrm{GW}$ total installed renewable energy capacity (IRENA 2020). Solar energy started the 2020 s poised to be a leading contributor to global low-carbon energy transitions, from leading countries such as China and India to entire global regions like the European Union, most of whose member states envisage significant roles for it in their National Energy and Climate Plans 2030.

Scholarship on solar energy has correspondingly burgeoned, in keeping with quite remarkable growth in the wider literature on energy and sustainability transitions. A strong growth area is notably energy social science research (Sovacool 2014; van Veelen et al. 2019), with a focus on governance, political economy, socio-technical and justice aspects. The expanding field of energy geographies (cf. Bridge et al. 2013; Hansen and Coenen 2015; Calvert 2016) further emphasises socio-spatiality, situatedness (Rutherford and Coutard 2014), multiscalarity (Sareen and Haarstad 2018) and infrastructure (Bolton and Foxon 2015). Research networks on sustainability transitions, energy social science and energy geographies have flourished, with several related journals having become wellestablished in parallel.

Yet lacunae persist despite, and perhaps due to, these rapid scholarly advances. The book this chapter is part of seeks to address two specific tendencies: a limited focus on the global South compared to the vast number of global North-based studies that dominate energy social science research, and a disjuncture between scholarship that focuses on rapid transitions and work that foregrounds justice concerns. This is not to say that no such attempts have been made: several energy scholars straddle contrasting regional contexts in their bodies of work and there is 
discernible interest in topics like deep, rapid and just transitions and deep, equitable decarbonisation (Newell and Mulvaney 2013; Healy and Barry 2017; Geels et al. 2017; Sareen 2020). At multiple scales, energy scholars note patterns of disparity left unaddressed or even exacerbated by ongoing energy transitions (Bouzarovski 2014; Sovacool et al. 2020). It is nonetheless fair to say that energy social science research could do with more integration of work that cuts across contrasting empirical contexts, cross-fertilises bi-directional insights between the global South and global North (Cherunya et al. 2020) and probes the effects of the major sociomaterial shifts currently taking place in energy sectors across the globe.

\section{Channelling research insights from Indian to Portuguese transitions}

This chapter contributes an attempt in the direction of integrating work across contrasting contexts, notably from the global South, which has led these developments, to the global North. As a starting point, it builds on research in western Indian states during 2016 (Sareen 2018; Sareen and Kale 2018) as part of a large comparative research project on the political economy of electricity distribution sectors in 15 Indian states (Dubash et al. 2018). In Sareen and Kale (2018), the authors draw from work on rapid solar energy rollout in two Indian states, Gujarat and Rajasthan, to discuss three dimensions of energy justice: affordability, equity, and inclusion and participation. This is consistent with generic conceptualisation of justice as recognition-based, distributive and procedural, respectively (Fraser 2009; also see Wood and Roelich 2020). Among the concerns Sareen and Kale (2018) raise in relation to just solar rollouts, energy federalism is notable: transitions are governed at multiple scales with overlapping domains, exhibiting a polycentricity that is applicable to much climate governance (Jordan et al. 2018). In these Indian cases, both the federal and state governments exercise authority over solar energy rollout, but other actors are co-constitutive of its governance: solar developers who procure and implement solar projects, agencies with a brief to accelerate transitions to low-carbon energy and alleviate energy poverty (e.g. by disbursing small-scale solar equipment to poor households with low energy access levels), private companies rolling out bottom-of-the-pyramid solar energy appliances and greenfield developers acquiring land for solar plants. This captures a very specific moment in solar energy rollout in India: Gujarat led this development as early as 2008, even prior to the national solar policy of 2011, and rapidly installed $1 \mathrm{GW}$ of solar capacity; the solar segment of Rajasthan's financially constrained energy sector had begun to take off by 2016, sowing the seeds for its position in 2020, when it is poised to take over the mantle of the clear leader in solar energy among all Indian states. For this chapter, this distinction between the first-mover and financially constrained follower is important.

Having identified some key patterns from the two Indian states based on Sareen and Kale (2018), the chapter next turns to a relatively financially constrained context in the global North, namely Portugal in Europe. Portugal has been one of the European leaders on renewable energy rollout, first with 
hydropower and then with a major wind power component during the 2000s. Like Gujarat, Portugal witnessed a big push for solar energy in 2008, when it briefly held the world record for the biggest solar plant which was then being developed with a $46 \mathrm{MW}$ capacity. This pales in comparison to the sort of solar plants that have come up since, which run into several hundred MW, and are often clustered as even larger solar parks that can exceed $1 \mathrm{GW}$. Yet it did not serve as the precursor to comparably rapid growth in Portugal, which was badly impacted by the economic recession during 2008-2015. Solar energy witnessed limited growth during this period. Installed capacity grew steadily and modestly: $175 \mathrm{MW}$ in 2011, $418 \mathrm{MW}$ in 2014, $673 \mathrm{MW}$ in 2018 (DGEG 2020). The first big jump only came in 2019, when cumulative installed capacity reached $914 \mathrm{MW}$. Of this, 527 MW was large-scale; by comparison, small-scale solar comprised 163 of 418 MW in 2014 and 387 of 914 MW by 2019 (DGEG 2020). There are several parallels between Portugal's experience with solar energy rollout and that of Rajasthan: financially constrained energy sectors (Sareen 2018; Sareen and Haarstad 2018), relatively high levels of energy poverty (in relation to their respective global regions, namely Europe and India; cf. Bhide and Monroy 2011; Sadath and Acharya 2017; Horta et al. 2019; Gouveia et al. 2018) and a delayed escalation of solar energy rollout entering 2020, with ambitious future targets. Whereas Rajasthan, with a population of over 75 million, envisages $50 \mathrm{GW}$ of installed solar energy capacity by 2025 , Portugal, with a population of 10 million, targets up to $10 \mathrm{GW}$ by 2027.

\section{Methodological cross-fertilisation through three drivers of scalar biases}

The chapter explores how insights on the governance of solar rollout from the Indian states relate to the Portuguese case. The mode of transferring insights was primarily methodological: solar rollout in Portugal was studied using an approach similar to Sareen and Kale (2018), but with a considerably expanded empirical basis. While the focus on solar rollout in the Indian states was tangential to a larger project on the governance of electricity distribution, the study in Portugal was part of an ongoing project commenced in April 2017 directly focused on solar rollout governance. Fieldwork in India featured 56 expert interviews in the electricity sector split evenly between the states over a span of two months; fieldwork in Portugal featured 80 expert interviews conducted during five months of data collection during 2017-2019, complemented by field visits to several solar plants and participant observation in relevant workshops, seminars and conferences. This empirical work is both multi-sited and multi-scalar and has served as the basis for various published (Sareen et al. 2018; Sareen and Haarstad 2018; Sareen and Grandin 2020; Sareen 2020) and upcoming articles. Thus while the book chapter reports limited new data, the focus is on explicating the insights generated through this cross-fertilisation of an approach, first applied in the global South, to study solar rollout governance in a global North context. Despite this generic distinction, which runs through the book, my argument does not use the cases as ones that are inherently different; as pointed out above, the solar rollout experience 
in Portugal has distinct parallels with the Indian states, especially Rajasthan, in terms of the financial constraints in both energy sectors.

The insights identified pertain to three drivers of scalar biases in the governance of solar rollout: (i) the socio-materiality of energy infrastructure, (ii) regulatory inertia and path dependence in the sector and (iii) political influence in sectoral development. The chapter explains the empirical grounding of these drivers and discusses them in relation to recent energy social science research. As a contribution to the overarching focus of the book, the chapter addresses how these drivers are relevant for balancing urgency and justice in the governance of multi-scalar solar projects. It is argued that the drivers are broadly applicable, particularly where energy sectors face tight financial constraints, a quite common state of affairs especially in global South contexts, but often also in the global North. The implication for energy policy is to explicitly enable solar rollout at lower scales like households and communities in order to advance salutary justice effects of energy transitions. Simultaneously, there is a need to streamline the bureaucratic and technocratic requirements for large-scale solar projects in order to enable rapid low-carbon energy transitions. These policies can be implemented in parallel by a range of diverse actors who together constitute the assemblage of solar rollout governance. The rapid developments in solar rollout in global South contexts like India mark a clear instance where energy social science research can widen its range, by taking on board the approaches and insights that emerge from such studies and mobilising them in place-specific ways in studies of solar rollout in varied global North settings.

The chapter is structured as follows. The next section presents the three drivers of scalar biases and locates them within recent research in the field of energy geographies. A subsequent background section discusses the governance of solar energy rollout in relation to these drivers, first briefly for the Indian states and then for Portugal. Next, an empirical and analytical section provides further insights into how these drivers manifest in Portugal based on a methodological approach adopted from the Indian study. A concluding discussion argues that such crossfertilisation of approaches from global South-focused studies to global North regions can enlarge the analytical range of energy geographies scholarship across contexts where energy transitions pose challenges of governance.

\section{Three drivers of scalar biases: socio-materiality, regulatory inertia and politics}

Renewable energy sources, most notably solar PV, have achieved and gone beyond electric grid parity in terms of cost competitiveness during the 2010s. Responsive to the increasing diffusion of low-carbon energy technologies, the field of energy geographies has grown rapidly (Bridge 2018). Whereas energy transitions are often discussed in terms of transitions from fossil fuels to low-carbon renewable energy sources, the dynamics within the renewable energy sector merit distinct attention. The emergence of these sources at particular scales is reciprocally related with energy geographies, i.e. with the geographies territorialised 
by and constitutive of energy infrastructure. Energy geographies define the spatial concentration (horizontal scales) and the multi-level decision-making (vertical scales) that give shape to new energy infrastructures; as these infrastructures emerge, they in turn reconfigure energy sectors, territorially remaking energy geographies. This recent but strong suite of scholarship offers numerous insights that overlap with and draw from other fields like science and technology studies, political economy and just transitions research on infrastructure and sustainability (Bridge 2018; Hess and Sovacool 2020; Newell and Mulvaney 2013). For the drivers of biases in solar rollout posited here, engagement with treatment of scalar aspects in these overlapping fields is fruitful.

Driver 1: Insofar as these scalar aspects pertain to the infrastructure itself, energy social science research foregrounds the socio-materiality of the electricity sector. To limit the scope of this discussion, the focus is limited to electricity, as the most relevant part of the energy sector for solar energy rollout. The generation, transmission and distribution of electricity is clearly a technical and material concern. It is moreover social in that it affects the everyday lives of people who use electricity in various forms for diverse purposes. The way that electricity is embodied and made available through energy infrastructure - based on decisionmaking by networked actors - defines the scope of its use, in terms of physical access, affordability, monitoring and measurement by and for a variety of actors. Thus, socio-materiality is one key driver.

Socio-materiality has received great conceptual and empirical attention from energy scholars of global North contexts. A notable example is an edited volume by Gailing and Moss (2016) that focuses on Germany, where the national energy transition ("Energiewende") has included explicit attention to aspects of scale, such as in moves toward urban scale ownership of energy sector infrastructure and services. Bridge et al. (2013) provide a comprehensive geographical conceptualisation of low-carbon socio-technical transitions in the UK. These contributions have made significant headway since Lawhon and Murphy (2012) pointed out the need for more attention to space and place in scholarship on infrastructure transitions. Yet they find fewer matches in global South contexts, especially beyond urban socio-material reconfigurations. In their consideration of landscapelevel energy solutions that are globally applicable, Kiesecker and Naugle (2017) attend to associated land use effects. Yet knowledge on how these effects, which vary by technology, are determined in the full range of global contexts merits broader examination. It is here that attention to socio-materiality in relation to scalar biases of solar energy rollout can help. The choice of technology is apt for such exploration, given the modular nature of solar PV, which can be installed at scales that range from a few panels for a single household to hundreds of hectares for large solar plants.

Driver 2: The supply- and demand-side functioning of this sector as well as the supply-demand interface is characterised by innovation and regulation, which continuously engage with and act on each other to bring about sectoral change. These activities pertain to legal and financial aspects, bureaucratic and technocratic requirements and the general codification and institutionalisation of the 
electricity sector. There is inevitably path dependence in these trajectories, which sets up the need for adaptive regulation; hence regulatory inertia is a second key driver.

Regulatory inertia has received attention in both global North and global South contexts. This is typically in political science work, where governance scholars recognise the potential limiting effects of path dependence in rapidly evolving sectors where infrastructure investments (thermal plants, transmission grids) typically span several decades (Lockwood et al. 2017; Cherp et al. 2018). Yet much of this work focuses on the role of governments; the field of energy geographies has shown that there are other actors who are relationally involved in co-shaping regulation, at urban (Haarstad 2016; Bouzarovski and Haarstad 2019), regional (Truffer and Coenen 2012) and translocal scales (Sareen and Grandin 2020). This recognition has taken hold amongst political scientists working on polycentric governance (Jordan et al. 2018). Sareen and Kale (2018) flag path dependence in relation to energy federalism, and Kivimaa et al. (2017) highlight the relevance of and distinct challenges to shifting governance practices at multiple scales as a concern in contemporary scholarship. An explicit focus on how regulatory inertia drives scalar biases in diverse contexts can advance this research.

Driver 3: During sectoral change, the field of actors is by definition also subject to change, as new entrants emerge and incumbents adapt their activities to retain relevance across scales. These dynamics of change are fraught, contingent and determined through relational processes whereby actors interact to contest and modulate changes in ways that best serve their self-interest and reduce their exposure to risk from uncertainty. These processes transcend the electricity sector into broader political and economic entanglements through which the sector is governed, with the allocation of benefits and burdens from energy infrastructure transitions in the balance. Thus, politics is the third key driver of scalar biases.

Politics is inextricably linked with changes in a sector as economically important as energy, often with numerous powerful incumbent interests. A recent trend in scholarship, as exemplified by Dubash et al. (2018), is to articulate the specific nature of such political influence. As the comparative work on electricity distribution governance across 15 Indian states has shown (Dubash et al. 2018), there is incredible variation even at sub-national scales. Most global or multicountry analyses do not probe such differences as they tend to compare like with like at the national scale; yet large countries such as India or China can exhibit rich diversity comparable to global regions like Europe, and their subnational regions have diverse political priorities (cf. Arndt et al. 2017), much like European Union member states (cf. Bouzarovski 2014). Yet few studies combine fine-grained contextualisation of political influence with analytical cross-fertilisation between global North and global South energy transitions. Approaching politics as a driver of scalar biases can direct attention to its effects on multiscalar sectoral transitions in diverse contexts and ease the challenging task of integration over time. 


\section{The governance of solar energy rollout: from India to Portugal}

The implications from the studies on two western Indian states (Sareen 2018; Sareen and Kale 2018) can be summed up in terms of these three drivers of scalar biases and related to the solar energy rollout in Portugal. At the time of these studies in 2016, both Gujarat and Rajasthan had heavy dependence on fossil fuels, based on domestic and international imports for coal thermal plants. They had to meet renewable energy source targets that ratcheted up annually and thus needed to install solar energy capacity. Land was easily available in the barren western reaches of both states, whereas energy demand was concentrated in urban and industrial centres. In terms of socio-materiality as a driver of scalar biases, this necessitated investment in transmission infrastructure to set up large solar plants far from centres of energy consumption, with row upon row of modules often spreading across tens or hundreds of acres. Portugal showed a similar dynamic with weakly developed grid infrastructure in its southern regions where the solar resource was highest (Sareen and Haarstad 2018). It, too, envisaged a move away from dependence on fossil fuel imports and - having built up hydro and wind power capacity - eyed solar expansion as technology costs declined.

Regulatory inertia was evident in the Indian states through the governance approach to solar energy rollout, which led to installing large, spatially concentrated solar plants that profited primarily large industrial actors (Yenneti and Day 2016; Yenneti et al. 2016; Sareen and Kale 2018). There was a continuing push for fossil fuels even as solar energy became economically competitive, despite new coal and gas investments effectively locking in high emissions for another three decades. Portugal saw similar parallel pushes for sectoral growth rather than a phase-out of fossil fuel dependence rapidly replaced by solar. Until 2018, consortia to start offshore oil exploration remained a distinct possibility, and two existing coal plants continued to have extended lifespans based on upgrade investments. Traditional allocation of limited grid capacity to fossil fuel plants held up licences for solar developers. Incentives for small-scale solar - defined in Portuguese legislation as plants up to $250 \mathrm{~kW}$ in size - were decreased after initial support and capacity only grew modestly for self-consumption during the late 2010s (Sareen et al. 2018). Thus, adaptive regulation was not evident to enable multi-scalar lowcarbon energy transitions.

Finally, politics featured heavily in both the Indian states and in Portugal. Gujarat adopted a strategy to heavily subsidise rapid solar growth early on, based on good sectoral finances and a top-down push to establish it as a solar leader (Sareen and Kale 2018; Chatterjee 2020). Rajasthan was reeling under financial constraints with repeated sectoral bailouts and took up large-scale solar through auctions once it achieved grid parity on costs. Portugal is a hybrid example of both approaches; it initially subsidised solar energy heavily, then curtailed such investment during the financial crisis of 2008-2015 and thereafter phased out subsidised feed-in tariffs to capitalise on the cost competitiveness of solar energy. Most notably, its July 2019 solar auctions set a new world record at the time, with a lowest bid below $€ 15$ per MWh and an average cost at two-fifths of the annual 
average rate on the wholesale electricity market (Sareen 2020). This will add 1.35 GW of cheap solar capacity to its grid by 2021 . Across cases, the political economy of these developments prioritised large-scale solar plants that made up the bulk of large additions, with limited growth in small-scale capacity.

Having given a brief comparative overview of the similar trends across these distinct yet comparable contexts in terms of the three drivers of scalar biases in solar energy rollout, the next section provides greater empirical analysis of developments in Portugal in terms of each driver.

\section{The drivers of scalar biases in Portuguese solar energy rollout}

This section sequentially analyses how the three drivers can deepen our understanding of solar energy rollout in Portugal, in ways enabled by adopting the methodological approach of the research conducted on the Indian states. As explained in the introduction (also see Sareen and Kale 2018), and also detailed in specific instances below, this approach centred on expert interviews conducted with energy sector stakeholders and brought a multi-scalar and multi-sited focus to solar energy rollout.

Socio-materiality: The main driver of solar rollout in Portugal was cost reduction in the solar PV technology. This is true globally, with the effects of developments as far away as China being felt directly at national and local scales. A representative from a regional ecological association discussed this in reference to a solar plant of over $200 \mathrm{MW}$ planned by an Irish-Chinese consortium in Alcoutim:

The environmental impact assessment suggested adding solar panels as one of the highlights along Via Algarvina [a heritage route affected by the solar plant], or making a detour in the Via Algarvina. ... The developer laid the foundation stone in early April 2017, with the Minister of Economy from Lisbon in attendance and other bigwigs from Faro [regional headquarter]. That was the first time the Chinese investor saw the landscape, I think, then tried finding alternatives. ... The Portuguese Environment Agency responds to a developer proposal by working many publicly paid hours to suggest an alternative proposal that the developer can then easily adopt, and it's already accepted before details become public. ... Our position is pro smaller plants, and that people should be encouraged to install solar solutions in their own households.

(interview dated 20 September 2017)

The modular nature of solar PV means that it can be installed at both large and small scales, with a wide range of spatial distribution or concentration in high solar irradiation regions. This distinguishes it from fossil fuels that require transport infrastructure and strong supply chains to ensure reliable generation. Yet this quote illustrates that this scalar scope was not exploited effectively. Rather, the impact of a large solar plant on the local context was imposed top-down by 
powerful actors. Clearly, political dynamics interplay with socio-materiality; these are discussed as the third driver below.

Other socio-material aspects of solar energy include temporal output profiles limited to sunlight hours and premium plant siting locations based on electric grid access. Hence, legacy electricity market pricing protocols and transmission infrastructure determine value propositions for solar developers. A solar developer summed up the challenges he faced during technological niche expansion:

The problem with current developments around solar energy in Portugal is that solar developers are being exposed to future risk. With an increase in the renewable energy component, the variable cost of energy generation will tend to zero. This means that energy purchase prices on a competitive market will witness substantial decrease. The problem for solar developers is that their investment today will buy less generating power at higher rates than competitors who might invest a couple of years in the future. ... The market has to move to incentivising flexibility. Instead, it is still rewarding steady base load and placing risk on those producing renewable energy which has more flux. This is the marginal cost based pricing logic of the market and it disfavours renewable energy.

(interview dated 28 September 2017)

These problems were compounded by material limitations of weak grid infrastructure in southern Portugal. While this limited the quantum of solar PV that could be installed, a European agreement to invest in strengthening grid infrastructure and expanding interconnections in 2018 improved future prospects, with further investments foreseen in the National Energy and Climate Plan 2030 in 2019.

Regulatory inertia: The past decade of solar PV trends demonstrate how vital regulations are towards shaping an industry and thus rapid energy sector transitions. Large-scale solar PV took off in Portugal due to energy policies that offered subsidies, which created the initial conditions for actors interested in this emerging sector to organise and prepare to grow such investment. Yet regulations did not maintain a consistent trajectory. Large solar PV developers had to go through messy processes to acquire solar PV plant licences and lacked clarity over the availability of the electric grid. One frustrated solar developer explained:

Right now grid capacity is stuck with big solar project licenses the government has given out in Ourique and Alcoutim, where the law could be applied to open that capacity up for small companies. But instead the companies with licenses take two years, then ask for a year extension on some basis, even knowing that they will need more time beyond that, which should be a breach but gets granted.

(interview dated 22 August 2018)

Small solar PV actors showed enthusiasm to invest in and install plants, but the incentives that attracted them were lowered too quickly and too much for 
continued growth. Small solar PV had a strong start in the 2010s, with attractive initial feed-in tariffs that were rapidly reduced, then renewed on a year-byyear basis from 2013 onwards. With early adopters and quick payoffs options exhausted, small solar PV prosuming to the grid came to a standstill at $170 \mathrm{MW}$. An early adopter of small-scale solar PV linked this with entrenched regulations that favoured the large incumbent company, EDP:

The problem we have now is how we can meet such a high level of ambition if you look at EDP which is the most important player in the country in terms of electricity production and they are investing zero in solar in Portugal besides supporting some self-consumption by small consumers, which is basically a business case for them. They do not want to build a power plant. And the reason is the way the market is working. If we want to reach the necessary level of ambition, you have to change the current market rules.

(interview dated 16 August 2018)

A self-consumption law imposed the limitation that solar PV generated had to either be consumed by a single user entity or injected to the electric grid in exchange for a nominal tariff set far below the retail electricity price. This made small-scale solar PV unattractive for those whose electricity consumption profiles did not match its production profile, such as small families with nobody home during main solar production hours. Adding energy storage was not yet cost-effective at household scale until 2020. Thus, small businesses and public buildings could not benefit from production during holidays. In short, small players could only invest in solar PV to sell electricity at very low rates to the grid while making savings on self-consumption by reducing their grid electricity consumption.

Thus at the large scale, regulations failed to provide a clear picture and actors were unfairly penalised in various ways, such as having to invest in greenfield development without then being able to procure a licence, and having to deal with lack of policy visibility by paying high interest rates for investment capital. Whereas at the small scale, regulations excluded actors from a fair option to share in installing and benefitting from solar PV plants. This inability or unwillingness to calibrate regulations to enable fair multi-scalar rollout terms halted small solar PV capacity after initially rapid growth.

Politics: The most decisive driver in terms of scalar biases, revealing transsectoral dynamics, proved to be politics. Poorly designed wind energy contracts by a government in the 2000s raised sectoral debt. This modulated decisions on solar PV during the 2010s in contrasting ways. First, renewable energy suffered a legitimacy crisis in public perception due to its weaponisation in political rhetoric, which the political opposition mobilised to come into power in 2011 (Sareen and Haarstad 2018; Sareen 2020). This government politically opposed renewable energy during a period of austerity politics. The Socialist Party, back in power in 2015, found subsidising renewable energy politically unviable, with squeezed fiscal room as Portugal sought to retain financial credibility and exit both the economic recession and deeply unpopular austerity measures. Hence, financial 
incentives to solar PV remained largely dry when these were still required for the technology to compete at market prices.

The formation of a new Ministry of Environment and Energy Transition in October 2018 and the re-election of the Socialist Party government in the October 2019 elections brought signs of evolution in solar energy governance after years of dithering. These developments mark the institutionalisation of a new appetite for low-carbon energy transitions. A ministry representative explained their approach:

Stated intent in solar has been $5 \mathrm{GW}$, but translated into not even $10 \%$, maybe $500 \mathrm{MW}$, due to grid constraints, financial constraints, investors speculating on licenses. So to achieve $47 \%$ renewable energy by 2030 compared to $31 \%$ by 2020 , which is a big jump, two procedures. First to attract foreign investors to come to Portugal, which is a challenging thing but also something where we are well positioned and also have experience with renewables although not with solar. [Second] we are looking at agriphotovoltaics and trying to not rely solely on large-scale solar. So we are looking at legislation on decentralised solar production, to open up for communities and local businesses. Right now one installation can feed a single consumer, with community energy all households in condominiums, all service buildings, can share with other consumers with complementary consumption patterns.

(interview dated 7 March 2019)

This policy push bore clear results for large-scale solar with successful solar auctions in July 2019 with competitive bids for $1.35 \mathrm{GW}$ that fetched a world record low price. A further $700 \mathrm{MW}$ of capacity was successfully concluded in August 2020 and set another world record. Consequently, large solar PV capacity in Portugal looks set to exceed $2 \mathrm{GW}$ by 2021. Legislation enabling energy communities came into force in January 2020, and while it is too early to comment on the effect here, this is a promising development for small-scale solar rollout. A solar energy researcher in Portugal pointed out that "there is a need for fungible models for community solar energy. Automation is clearly part of the way forward, time-of-use is too much of a demand for ordinary people. You cannot bother with waiting till 10pm when you have a little child" (interview dated 6 March 2019). Attention to politics and changing power dynamics as a driver thus directs focus to questions of grid digitalisation, new economic models and how new laws will be operationalised and implemented.

Adoption of technical measures like the solar auctions and small-scale solar PV laws has insulated it from national politics. Two vision documents launched in 2019 underscore this: a National Energy and Climate Plan 2030 and a Carbon Neutrality Roadmap 2050. These specify ambitious solar targets - up to $9 \mathrm{GW}$ by 2027 - for Portugal to decarbonise electricity and systematically electrify other sectors.

Thus, solar energy rollout in Portugal has so far been geared towards big solar developers, who can mobilise millions of Euros in investment, to the detriment of 
participation by smaller players. Yet there are signs of emerging efforts to address such scalar biases. Arguments that support scalar biases include: easier coordination of electricity markets in a highly connected technological sector with massive grid infrastructure; easier monitoring and regulation with a small number of large players; and economies of scale for economic competitiveness. Equally, there are reasons to be wary of such a scalar bias. An oligopoly by large actors can: subdue interest in technologies and scales of deployment that are socio-ecologically desirable; enable exploitation of regulatory lags to abuse control over electricity infrastructure and exclude smaller players; and maintain high prices instead of translating cost declines in solar PV technologies into societal benefits.

\section{Implications for balancing urgency and justice in solar energy rollout}

The concluding discussion reflects on the cross-fertilisation of a methodological approach from a study focused on the global South to a global North context. It is argued that the results that ensued have enlarged the analytical range of energy geographies scholarship across contexts where energy transitions pose challenges of governance. This enlargement takes the form of three drivers of scalar biases during solar energy rollouts that can be analytically generative in a wide range of contexts. While they inevitably overlap, the drivers capture distinct core dynamics that modulate the expression of scalar biases during solar rollout. As the drivers point to tendencies that are found in all low-carbon energy transitions and manifest in diverse situated ways, a variety of studies that employ these drivers will increase their explanatory power across global South and global North contexts. This can be a step towards a more integrated field of energy geographies research, where we can move beyond binaries such as global South and global North and engage with the richness of socio-spatial patterning interlaced across contexts.

The implications of the drivers go beyond this integrative push. They speak directly to the overarching aim of this book, which focuses on balancing concerns of urgency and justice in relation to ongoing low-carbon energy transitions. Solar energy rollout foregrounds this tension in terms of scalar biases evident in the Indian and Portuguese cases discussed above. Rapid rollout takes the form of large-scale solar plants that contribute little to socio-economic justice even as they accelerate climate change mitigation. This is not inevitable; nevertheless, analysis of the governance of solar energy rollout displays a strong bias in favour of such large-scale infrastructural shifts benefitting primarily large actors and entrenched modes of sectoral operation. At the same time, small-scale solar rollout remains quite modest and steady rather than scaling up, which limits its impact for climate change mitigation. The drivers of scalar bias again foreground reasons for this, in terms of the socio-materiality of the energy sector, its regulatory inertia and the nature of political influence, which combine to impose bureaucratic and technocratic barriers to rapid expansion of small-scale solar energy initiatives.

There are notable similarities in how these trends play out in India and Portugal, which suggests that closer analytical attention to global South and 
global North contexts may increase the explanatory power of energy transition studies across contexts. The challenges present themselves differently in notable ways across contexts - India's sheer population numbers and lower energy development level dictate a need to expand energy access rapidly, accompanied by political economic implications, whereas Portugal's isolated geography places limits on electric grid interconnections. Yet the drivers that modulate decisions across these contexts are qualitatively similar. This congruence of scalar biases across contexts suggests that the drivers themselves are what underlie the dilemma between urgency and justice in energy transitions. In other words, the dilemma is one premised on entrenched modalities of governance and energy infrastructure. Without addressing these situated questions of infrastructure, regulation and politics, low-carbon energy transitions are unlikely to achieve justice.

In the Portuguese case, an analysis using the three drivers identified these key areas to focus on for future changes to multi-scalar solar energy rollout: the implementation of new community energy legislation, the performance of future innovatively designed solar PV auctions and the expansion of limited electric grid infrastructure in conjunction with installing solar capacity. This approach does not treat scalar biases as an end in themselves or simply evaluate them as a negative phenomenon. Rather, by taking point of departure in scalar biases and seeking to explain them, they are treated as widespread characteristics of energy transitions that can provide vital analytical entry points to identify governance challenges of a given energy transition case. Future research that employs the same drivers - socio-materiality, regulatory inertia and politics - or a different configuration of variants adapted to other cases can test how much further it is possible to extend the explanatory power of such an approach and whether it can be generalised to all energy transitions. Given that energy is a deeply political sector, that energy infrastructure is irrefutably socio-material and that rapid evolution inevitably courts the risk of regulatory inertia that lags behind innovation in their reciprocal relationship, these drivers are likely to yield deep explanation of energy transitions.

\section{References}

Arndt, C., Miller, M., Tarp, F., Zinaman, O. and Arent, D., 2017. The Political Economy of Clean Energy Transitions. Oxford, Oxford University Press.

Bhide, A. and Monroy, C.R., 2011. Energy poverty: a special focus on energy poverty in India and renewable energy technologies. Renewable and Sustainable Energy Reviews, 15(2), pp.1057-1066.

Bolton, R. and Foxon, T., 2015. Infrastructure transformation as a socio-technical process: implications for the governance of energy distribution networks in the UK. Technological Forecasting and Social Change, 90, pp.538-550.

Bridge, G., 2018. The map is not the territory: a sympathetic critique of energy research's spatial turn. Energy Research \& Social Science, 36, pp.11-20.

Bridge, G., Bouzarovski, S., Bradshaw, M. and Eyre, N., 2013. Geographies of energy transition: space, place and the low-carbon economy. Energy Policy, 53, pp.331-340. 
Bouzarovski, S., 2014. Energy poverty in the European Union: landscapes of vulnerability. Wiley Interdisciplinary Reviews: Energy and Environment, 3(3), pp.276-289.

Bouzarovski, S. and Haarstad, H., 2019. Rescaling low-carbon transformations: towards a relational ontology. Transactions of the Institute of British Geographers, 44(2), pp.256-269.

Calvert, K., 2016. From 'energy geography' to 'energy geographies' Perspectives on a fertile academic borderland. Progress in Human Geography, 40(1), pp.105-125.

Chatterjee, E., 2020. New developmentalism and its discontents: state activism in Modi's Gujarat and India. Development and Change, in press, https://doi.org/10.1111/dech .12579 .

Cherp, A., Vinichenko, V., Jewell, J., Brutschin, E. and Sovacool, B., 2018. Integrating techno-economic, socio-technical and political perspectives on national energy transitions: a meta-theoretical framework. Energy Research \& Social Science, 37, pp.175-190.

Cherunya, P.C., Ahlborg, H. and Truffer, B., 2020. Anchoring innovations in oscillating domestic spaces: why sanitation service offerings fail in informal settlements. Research Policy, 49(1), 103841.

DGEG (Directorate General for Energy and Geology) 2020. Renewables Summary Statistics 183: February 2020. Accessed on 27 April 2020 at http://www.dgeg.gov.pt.

Dubash, N., Kale, S. and Bharvirkar, R., eds., 2018. Mapping Power: The Political Economy of Electricity in India's States. New Delhi, Oxford University Press.

Fraser, N., 2009. Scales of Justice: Reimagining Political Space in a Globalizing World. New York, Columbia University Press.

Gailing, L. and Moss, T. eds., 2016. Conceptualizing Germany's Energy Transition: Institutions, Materiality, Power, Space. London: Palgrave.

Geels, F.W., Sovacool, B.K., Schwanen, T. and Sorrell, S., 2017. Sociotechnical transitions for deep decarbonization. Science, 357(6357), pp.1242-1244.

Gouveia, J.P., Seixas, J. and Long, G., 2018. Mining households' energy data to disclose fuel poverty: lessons for Southern Europe. Journal of Cleaner Production, 178, pp.534-550.

Haarstad, H., 2016. Where are urban energy transitions governed? Conceptualizing the complex governance arrangements for low-carbon mobility in Europe. Cities, 54, pp.4-10.

Hansen, T. and Coenen, L., 2015. The geography of sustainability transitions: review, synthesis and reflections on an emergent research field. Environmental Innovation and Societal Transitions, 17, pp.92-109.

Healy, N. and Barry, J., 2017. Politicizing energy justice and energy system transitions: fossil fuel divestment and a "just transition". Energy Policy, 108, pp.451-459.

Hess, D.J. and Sovacool, B.K., 2020. Sociotechnical matters: reviewing and integrating science and technology studies with energy social science. Energy Research \& Social Science, 65, 101462.

Horta, A., Gouveia, J.P., Schmidt, L., Sousa, J.C., Palma, P. and Simões, S., 2019. Energy poverty in Portugal: combining vulnerability mapping with household interviews. Energy and Buildings, 203, 109423.

IRENA 2020. Renewable Energy Statistics 2020. Abu Dhabi: International Renewable Energy Agency.

Jordan, A., Huitema, D., Van Asselt, H. and Forster, J. eds., 2018. Governing Climate Change: Polycentricity in Action? Cambridge, Cambridge University Press.

Kiesecker, J. and Naugle, D. 2017. Energy Sprawl Solutions: Balancing Global Development and Conservation. Washington DC, Island Press. 
Kivimaa, P., Hildén, M., Huitema, D., Jordan, A. and Newig, J., 2017. Experiments in climate governance-a systematic review of research on energy and built environment transitions. Journal of Cleaner Production, 169, pp.17-29.

Lawhon, M. and Murphy, J.T., 2012. Socio-technical regimes and sustainability transitions: insights from political ecology. Progress in Human Geography, 36(3), pp.354-378.

Lockwood, M., Kuzemko, C., Mitchell, C. and Hoggett, R., 2017. Historical institutionalism and the politics of sustainable energy transitions: a research agenda. Environment and Planning C: Politics and Space, 35(2), pp.312-333.

Newell, P. and Mulvaney, D., 2013. The political economy of the 'just transition'. The Geographical Journal, 179(2), pp.132-140.

Rutherford, J. and Coutard, O., 2014. Urban energy transitions: places, processes and politics of socio-technical change. Urban Studies, 51(7), pp. 1353-1377.

Sadath, A.C. and Acharya, R.H., 2017. Assessing the extent and intensity of energy poverty using multidimensional energy poverty index: empirical evidence from households in India. Energy Policy, 102, pp.540-550.

Sareen, S., 2018. Energy distribution trajectories in two Western Indian states: comparative politics and sectoral dynamics. Energy Research \& Social Science, 35, pp.17-27.

Sareen, S., ed., 2020. Enabling Sustainable Energy Transitions: Practices of Legitimation and Accountable Governance. Cham, Palgrave Macmillan.

Sareen, S., Baillie, D. and Kleinwächter, J., 2018. Transitions to future energy systems: learning from a community test field. Sustainability, 10(12), 4513.

Sareen, S. and Grandin, J. 2020. European green capitals: branding, spatial dislocation or catalysts for change? Geografiska Annaler: Series B, Human Geography, 102(1), pp.101-117.

Sareen, S. and Haarstad, H., 2018. Bridging socio-technical and justice aspects of sustainable energy transitions. Applied Energy, 228, pp.624-632.

Sareen, S. and Kale, S.S., 2018. Solar 'power': socio-political dynamics of infrastructural development in two Western Indian states. Energy Research \& Social Science, 41, pp. $270-278$.

Sovacool, B.K., 2014. What are we doing here? Analyzing fifteen years of energy scholarship and proposing a social science research agenda. Energy Research \& Social Science, 1, pp.1-29.

Sovacool, B.K., Hook, A., Martiskainen, M., Brock, A. and Turnheim, B., 2020. The decarbonisation divide: contextualizing landscapes of low-carbon exploitation and toxicity in Africa. Global Environmental Change, 60, 102028.

Truffer, B. and Coenen, L., 2012. Environmental innovation and sustainability transitions in regional studies. Regional Studies, 46(1), pp.1-21.

Van Veelen, B., Pinker, A., Tingey, M., Aiken, G.T. and Eadson, W., 2019. What can energy research bring to social science? Reflections on 5 years of Energy Research \& Social Science and beyond. Energy Research \& Social Science, 57, 101240.

Wood, N. and Roelich, K., 2020. Substantiating Energy Justice: creating a Space to Understand Energy Dilemmas. Sustainability, 12(5), 1917.

Yenneti, K. and Day, R., 2016. Distributional justice in solar energy implementation in India: the case of Charanka solar park. Journal of Rural Studies, 46, pp.35-46.

Yenneti, K., Day, R. and Golubchikov, O., 2016. Spatial justice and the land politics of renewables: dispossessing vulnerable communities through solar energy mega-projects. Geoforum, 76, pp.90-99. 